\title{
Perception of People Living with HIV and AIDS Regarding Home Based Care in Malawi
}

\author{
Mercy Pindani ${ }^{1}$, Alfred Maluwa ${ }^{1 *}$, Makhubella Nkondo ${ }^{2}$, Betty Mkwinda Nyasulu ${ }^{1}$ and Winnie Chilemba \\ ${ }^{1}$ Kamuzu College of Nursing, University of Malawi, Lilongwe Campus, P/Bag 1, Lilongwe, Malawi \\ ${ }^{2}$ University of South Africa, Cnr Walker and Mears Streets, Sunnyside, Pretoria, 0002, South Africa
}

\begin{abstract}
Results are presented of perception of the people living with HIV and AIDS regarding home based care in Malawi. The study was conducted in Lilongwe from April to May, 2009. The participants were people living with HIV and AIDS and were drawn from 3 organizations that deal with people living with HIV and AIDS. These organizations were: Light House, National Association for People Living with HIV and AIDS in Malawi and Lilongwe Diocese. Purposive sampling technique was used to choose people living with HIV and AIDS who had rich experience on home based care. Data was collected through in-depth interviews with the participants using an open ended interview guide. Data saturation was reached when in-depth interviews were conducted with 15 people that were living with HIV and AIDS. Qualitative data was analyzed using ATLAS ti5.0. The participants reported that most of the home based care was rendered by close relatives who were mostly immediate family members such as spouses, daughters, mothers, sisters and brothers. The perception of the participants was that health care workers and volunteers only complemented the care provided by the close family members weekly or fortnightly. They also complained that the biggest challenge with home based care was stigma and discrimination by other community members and distant relatives. They further complained that most care providers lacked knowledge and resources for home based care. It is therefore recommended that the various stakeholders in Malawi such as government, community volunteers and non-governmental organizations support and train the home based care givers.
\end{abstract}

Keywords: People living with HIV and AIDS; Home based Care; Community based services; HIV and AIDS patient care givers; HIV and AIDS service providers

\section{Introduction}

Malawi, like any other country in the Sub-Saharan Africa faces the global challenge of HIV and AIDS. The prevalence of HIV in Malawi is at $10.6 \%$ [1] which is one of the highest in the world. This high prevalence rate has over stretched the health care system due to lack of resources, few number of hospital beds and limited number of health workers in the health facilities. AIDS accounts for more than $60 \%$ of all in-patient admission [2]. In addition, the pandemic also complicates efforts to deal with growing cases of opportunistic infections such as Tuberculosis (TB). People living with HIV and AIDS face many challenges including stigma and discrimination. In most cases HIVrelated stigma and discrimination severely hamper efforts to effectively fight the epidemic. Stigma remains the single most important barrier to public action [3]. In addition, many people are afraid to see a doctor or present themselves for voluntary HIV testing and counselling or seek treatment when they are HIV positive due to stigma. Hence stigma contributes to making AIDS the silent killer, because people fear the social disgrace of speaking about it, or taking available precautions, hence the AIDS epidemic has continued to devastate societies around the world [3].

Most of the chronically ill patients go home when they are discharged while on-going care is still required. For this reason, home based care for chronically ill patients is one of the suitable interventions in the care and support for HIV and AIDS patients [2,4]. Although home based care is ideal, most families face social and economic challenges. Lack of resources like food and transportation are the major obstacles in providing care to People Living with HIV and AIDS [4].

The formal Community and Home Based Care (CHBC) services for People Living with HIV and AIDS (PLWHA) in Malawi were initiated through the National AIDS Commission in 2001as a result of the high number of AIDS cases in the country [4]. The provision of effective community based care therefore, became a priority as well as an absolute necessity. Consequently, communities have mobilized themselves and are proving care for PLWHA using their own resources in their homes [5]. The goal of CHBC is to make appropriate quality health services available to all chronically ill people and other vulnerable groups in the community [6]. The CHBC renders a high level of social support which is associated with coping and treatment adherence among the HIV patients [7]. Although providing home based care to PLWHA is a rewarding experience, it can be stressful, depressive and frustrating [8]. Information on the quality of home based care in Malawi as perceived by PLWHA is scanty. Therefore, the study aimed at exploring the roles and attitudes of various care givers as perceived by PLWHA during home based care in Malawi.

\section{Methodology}

A hermeneutical phenomenological research design, which studies interpretive structures of experiences, was used in the study to examine the real life experiences of the PLWHA. The study utilized qualitative method to explore and understand the experiences of PLWHA and give them meaning [9]. A purposive sampling technique was used to choose participants who had rich information needed for gaining an

*Corresponding author: Alfred Maluwa, Kamuzu College of Nursing, University of Malawi, Lilongwe Campus, P/Bag 1, Lilongwe, Malawi, E-mail: aomaluwa@kcn.unima.mw

Received February 26, 2013; Accepted March 27, 2013; Published March 31 2013

Citation: Pindani M, Maluwa A, Nkondo M, Nyasulu BM, Chilemba W (2013) Perception of People Living with HIV and AIDS Regarding Home Based Care in Malawi. J AIDS Clin Res 4: 201. doi:10.4172/2155-6113.1000201

Copyright: $\odot 2013$ Pindani M, et al. This is an open-access article distributed under the terms of the Creative Commons Attribution License, which permits unrestricted use, distribution, and reproduction in any medium, provided the original author and source are credited. 
insight and discovering new meaning of issues that specifically affected the PLWHA as they were under-going CHBC. The experiences were obtained using an in-depth interview guide and data saturation was achieved after interviewing 15 participants that were drawn from 3 major organizations that deal with PLWHA in Lilongwe district. The organizations were Light House, which is a public institution, the National Association for People Living with HIV and AIDS in Malawi (NAPHAM), a civil society organization and the Lilongwe Diocese which is a faith based organization. These organizations use the same policy document on Home based care guidelines that are provided by the government of Malawi through the Ministry of Health [10].

\section{Inclusion and exclusion criteria}

To be recruited for the study, participants had to be at least 14 years, living with HIV and AIDS and enrolled into a CHBC in Lilongwe district for at least 6 months. All HIV negative persons or PLWHA from other districts other than Lilongwe and PLWHA in Lilongwe but not enrolled in the CHBC program or those enrolled but were below the age of 14 years were excluded from the study.

\section{Ethical consideration}

The study was approved by the internal review boards of the University of South Africa (UNISA) and the University of Malawi's College of Medicine Research and Ethics Committee (COMREC). Permission to access the PLWHA was obtained from heads of the institutions of Light House, NAPHAM and Lilongwe Diocese. Informed consent was obtained from each participant who met the inclusion criteria. For the minors, informed consent was obtained, in addition, from their parents or guardians. The identity of the participants has not been disclosed and the participants were allocated numbers 1 to 15 for their reference to ensure anonymity.

\section{Data collection}

An in depth interview was conducted by a registered nurse who is also a faculty member of Kamuzu College of Nursing and at the time a PhD student at University of South Africa. She was assisted by two trained research assistants. The participants were identified from the three institutions in Lilongwe and those that met the inclusion criteria and consented to the study were interviewed at a private place within their homes. For the minors, i.e., those below 18 years of age, consent was also obtained from their parents before they were interviewed. During data collection, each participant was engaged in a dialogue using an open ended interview guide. Probes were made to understand the participants' responses and comments on an issue under discussion. The discussions concentrated on the type and extent of the care that PLWHA received at home. Specifically, information was collected regarding perception of the care they received, their lived experiences and their perceptions of the $\mathrm{CHBC}$ program. A digital recorder was used to record the discussions and field notes were manually taken to aid the data collection process. The field notes included the mood and behaviour of the participants during interviews and the interviews lasted between 45 and 60 minutes.

\section{Data analysis}

During data analysis, the interviews were transcribed verbatim. The transcribed text was imported into Atlas ti 5.0 for further analysis. The narrative qualitative data was then organized and integrated according to emerging themes and concepts. The first step involved creating a project or a hermeneutic unit to enclose all the findings, codes, memos and structures. Then data files were assigned. The transcribed data from each interview were read and key words and significant statements were selected and reviewed. Words with similar meanings were placed into categories and then into themes. The code directorate was used to check whether the definitions of the codes were true and valid. The code directorate also helped to interpret the findings by attaching meaning and significance to the analysis. The emerging themes are reported as results.

\section{Results}

\section{Demographic characteristics of the participants}

Most of the participants $(53 \%, n=8)$ were aged between 26 and 45 years, while $27 \%, n=4$ were aged between 19 and 25 years. The teenagers comprised $7 \%, \mathrm{n}=1$ and those aged between 46 and 60 years $(13 \%, \mathrm{n}=2)$ were few. There were more female $(60 \%, n=9)$ than male $(40 \%, n=6)$ participants. The majority of the participants were female housewives $(40 \%, n=6)$. Those engaged in small businesses were $20 \%, n=3$. Another $20 \%, n=3$ were employed while $13 \%, n=2$ were pensioners and $7 \%, n=1$ did not have any occupation. Regarding literacy and numeracy, $80 \%$, $\mathrm{n}=12$ were literate and numerate. The marital status of the participants show that $40 \%, \mathrm{n}=6$ were married, while $13 \%, \mathrm{n}=2$ were single and another $13 \%, \mathrm{n}=2$ were divorced. The widows comprised $27 \%, \mathrm{n}=$ while only $7 \%, \mathrm{n}=1$ was a widower.

\section{Emerging themes}

A total of three major themes emerged from the participants' narrations. These were:

\section{Perception of PLWHA on their care providers}

2. Perception of PLWHA on the attitudes of care providers towards PLWHA

3. Perception of PLWHA on the community home based care program in Malawi

Perception of PLWHA on their care providers: All participants were cared for by either a close family member or a spouse. The health care workers and volunteers complimented the care given by close family members by weekly or fortnightly visits to the PLWHA's home. The majority of the care givers were female as narrated by a 40 year old male participant: "My wife is my main helper and she provides most of the care because I am with her most of the times." Daughters, although still in school, were assisting their mothers to care for their sick fathers as narrated by 45 year old male participant: "I have five children and the first born daughter assists her mother in providing care to me. Otherwise everybody in our house takes part in assisting me although my main carer is my wife."

Narrations from widowers indicated that their daughters, some of whom were in their teen ages, took care of them. A 48 year old widower said that: "My daughter does most of the care. She cooks and gives me food. She cares for the home and the whole house though she is only 14 years old". The role of married daughters in caring for their sick fathers necessitated their re-location to the patient's home to effectively provide care, as narrated by a 48 year old widower.

"My daughter is 17 years and married. She agreed with her husband to come and stay near my house so that she could take care of me adequately. She is very good because she makes sure that I receive good care even in times when my volunteer is with me, my daughter makes sure that she is around too". 
Those daughters who were still in school had to forgo their school lessons to fulfil their role as care givers, especially when their fathers were admitted at the hospital as narrated by a 40 year old male participant.

"My relatives take me to the hospital when there is need to do so but when I am admitted nobody stays at the hospital except my daughter and that means she absents herself from school during those days. I still thank my relatives because they do a lot of things for me in addition to what my daughter does every day".

Regarding volunteers and health workers, their roles complemented activities of the close family members and they visited the participants at regular intervals. The volunteers were a source of moral support, but did not provide actual and daily care as narrated by a 36 year old female participant.

"If you talk of the volunteer, yes, she comes but it is only once a week and most of the times she finds that my relative has already done everything so she just chats with me. Her presence relieves my relative anyway."Another 40 year old female participant had this to say; " $m y$ elder sister and my daughter assist my husband to give care to me. My volunteer visits me once or sometimes twice a week".

In Malawi, the father is supposed to be the bread winner. In cases where the father is sick, the big challenge to the family is lack of basic resources for the home, as narrated by a 39 year old male:

"My wife looks after me. She cooks food and eats with me. She provides water for my bath and when I am weak she bathes me. My wife is my friend and therefore she makes sure that I am always happy. The main problem that we always face is lack of resources, as you know I am not working, and I am bed ridden so in most of the cases we run out of basic resources such as food. Sometimes, community members bring some resources like water, firewood and sometimes they chat with me when I am able to do so."

Perception of PLWHA on the attitude of their care providers towards PLWHA: The narrations of participants suggest that care givers who were close family members did not show any negative attitudes towards them. However, as the illness progressed, the community members and distant relations, developed negative attitudes towards the PLWHA. Thus, the nature and type of the relationship determined the resilience of the care giver towards the participant as explained by a 46 year old woman.

"I have problems with the attitude of my relatives which keep on deteriorating every day. I know they change their attitude everyday because they are getting tired of me and my sickness. But so far I haven't noticed any change in the attitude of my husband, and my children who are my main care providers."

The problem with distant relations and community members in caring for the PLWHA was also shared by a 28 year old woman:

"When I am admitted at the hospital nobody stays at the hospital except my daughter and my volunteer who comes often to see me in the hospital. My relatives don't even visit me until I come back home. I know they have negative attitude towards me because of my HIV positive status." Regarding my caregivers who happen to be members of my family I have no problems with their attitude may be they will start later but not now because they are caring for me very well. But few friends I think they discriminate against me but this is normal I have no problem with that."

Community members and close family members as caregivers need information on HIV prevention and care, access to basic supplies, training and referrals for medical care, as well as social assistance to support the PLWHA in their communities. In this study, most of the community members including the close relatives that were actually caring for the PLWHA did not receive any training as narrated by a 48 year old woman.

"None of my relatives have received any education concerning my care at home. This is very unfortunate because I have heard them sometimes discussing among themselves regarding what to do especially when I am very sick."

The lack of training for the care givers has compelled some of them to use their intuition, common sense or some knowledge they acquired elsewhere in dealing with situations that arose during the care of PLWHA as explained by a 43 year old woman:

"My daughter uses her own knowledge with the help of other relatives in order to give care to me but I know she would do much better if she received the education. Please madam, speak on our behalf that our carers should receive the training you are talking about, it sounds interesting and important".

Some care givers however, received information at the hospital as they were looking after their patients when they were hospitalized as explained by a 17 year old female; "Yes, my mother was given some information concerning my care but that was when we were still in the hospital before I was discharged. With any illness, education is very important. How do you expect these young ones who are taking care of us to know how to do a good job in caring without specific training?"

Perception of PLWHA on the community home based care program in Malawi: The majority of the participants explained that home based care was more beneficial to them than hospital based care. They explained that during the home based care the PLWHA are in the company of family members who care for and give them support. Home based care also provides an opportunity for the carers to undertake other household chores. In addition, participants explained that home based care prevented them from getting infected with other diseases from fellow patients due to congestion in hospital wards, as narrated by a 35 year old female participant:

"Madam, here at my house I am happy and free to do anything that I want such as to go outside if I want to bask in the sun but this was not the same when I was at the hospital. At the hospital, only my daughter was with me and I wished to see my other children but they could not come because they had no money for transport. Here at home I have most of my relatives with me and I feel better to be nursed at home than at the hospital. When you are at home the environment is different, you don't fear anything but at the hospital we are afraid of nurses who shout at patients because they feel the patients are difficult and troublesome. Besides, at the hospital there is a high chance of getting infected from fellow patients because the wards are always congested."

Some participants however, viewed hospital based care better than home based care. These participants felt that home based care has a lot of challenges. For this reason, it was better for them to be cared for at a health facility as narrated a 50 year old male participant:

"Home based care is a burden to relatives and family members. The care givers get tired of looking after a sick relative. At a health facility, doctors and nurses are always available to assist each other and drugs are available 3 times a day and the doctors can change prescription anytime when need arises."

A 58 year old female participant supported the hospital based care, 
explaining that "When a patient becomes sick and needs health facility services, usually with patients under home based care, referral is not done on time due to lack of transport. In some cases it takes up to a week before one is taken to the hospital."

Lack of food and other resources such as transport, were other reasons that made some participants prefer health facility care to home based care as explained by a 38 year old male participant "When there is no food at home we sleep on empty stomach. At the hospital there is always food available. When you are not feeling well and you are at home, it is not easy to access the hospital immediately due to lack of transport or money to hire a vehicle to go to the hospital on time. We reach the hospital after a long time has elapse from the time that the need for hospital care arose."

Stigma and discrimination was a major problem with home based care. Almost all participants mentioned it. In most cases the source of the stigma and discrimination were distant relatives, friends and other community members. Close family members were sympathetic and very supportive. This was shared by a 32 year old female participant

"Stigma and discrimination is the biggest problem that we face in the villages. When people discover that you are HIV positive, you lose friends, even some of the best friends shun you. Sometimes even when you call for a close friend, they reply saying that they are not around.... they have gone away... when in actual fact, they are available but they just do not want to be associated with you anymore. Gossip is also another challenge, relatives, friends and even fellow church members gossip a lot. The biggest source of stigma and discrimination is unfortunately our own distant relatives and they are the same people that are expected to provide care to us. As a result, the home based care burdens only the close family members such as spouses and children."

\section{Discussion}

In Malawi, like in many other African countries the high prevalence rate of HIV has necessitated the introduction of home based care. This is because the health facilities are not able to cope with the high demand for hospital bed space. Results show that PLWHA perceive that home based care is functional in Malawi, although it has challenges. Like all other Sub Sahara African countries, home based care has enormous challenges which need to be resolved to improve the quality of care to PLWHA. Lack of resources, stigma and discrimination were major obstacles for most PLWHA in this study.

The home based care in Malawi also faces inadequate support structures for care givers [11]. In support of this, Chikalipo [12], reported that most home based care support groups are located in the urban and peri-urban centres because of the proximity to the NGOs and faith based institutions to which they are affiliated. In addition, independent support groups are also located within the proximity of persons that facilitated the formation of the groups rather than where the PLWHA are found [4]. In view of this, the home based care programmes are located in places that are not most convenient to the PLWHA making it difficult for PLWHA to access the services.

In this study there was high level of support from close family members. According to Miller [13] family support is associated with better adjustment and coping treatment adherence during home based care of PLWHA. The results that close family members especially the wives and daughters were actively involved in the home based care for PLWHA agree with those reported by Yousef and Wong [14]. Results imply that the current shift of health service emphasis from hospital based care to home based care had affected family members' responsibility for proving direct care at home to their relatives. In almost all countries including Malawi, the family has always been a major provider of long term care for patients with chronic conditions including HIV and AIDS.

Home based care on the other hand has placed the heavy burden of care on the families alone which should not have been the case [15]. The wives in this study had to forgo some of their daily chores to care for their beloved chronically ill HIV and AIDS patients. Due to increased demand for patient care, many female care givers had less time to earn an income, produce food and look after the rest of the members of the household. Young girls at times missed school lessons because they had to take care of their sick fathers during hospitalization. Consequently a vicious cycle of poverty and poor health is created which increases further the risk of HIV infection [12].

In most parts of the country, communities have mobilized themselves and are providing care for the PLWHA. The important local resources are the community members themselves [6]. However, as more individuals are living with the HIV virus, more people are needed to provide the services. Providing services for people with HIV and AIDS is a rewarding experience, but it is stressful, leading to depression and frustration especially when the care givers are not trained. In this study, lack of training for the care providers affected the quality of care for the participants as shown by the participants' narration that at times they overheard their care providers discussing how to deal with their situation especially when they became very sick. Patient satisfaction with care has gained widespread recognition as an important indicator of quality of care that patients receive. It allows the provider to evaluate the degree of quality that patients find in their care by addressing critical psychological factors that characterize the interaction between patients and providers [16]. Therefore lack of training of the care givers in this study compromised the quality of care.

The negative attitude of community members towards PLWHA is caused by lack of knowledge. Although patients are being cared for at home, community members as carers are not well informed and are ill prepared about what to do. The concept of home based care places the responsibility for caring of the patients in the hands of the community members and not the family alone. In Malawi, knowledge about HIV and AIDS among communities is high, but the people do not provide quality home based care because of fear and misconceptions about the disease [17]. In addition, limited knowledge on home based management of PLWHA created fear among the home based carers [18]. Consequently, the PLWHA are shunned by friends and other community members. These results are supported by a study in Botswana [19] where families that received detailed information about the condition of patients manifested more vigilant coping skills compared with families that had little information. Thus the negative attitude of the community members may have been created due to hoarding of information by the close family members. Usually close family members bear the burden of home caring for their patients because they live in secrecy, tend to hide their patients and do not share their family member's diagnosis with the extended family relations [20]. As a result there is speculation, mistrust and gossip among the community members.

The positive perceptions of the PLWHA on the home based care were mainly due to their desire to be among family members at home while receiving care for their chronic illness. In addition, the participants' responses showed that most of them did not like the hospital care due to congestion which created a risk of contracting other diseases from fellow patients. Results show that the patients who found greater peace in accepting and coping with AIDS at home were 
Citation: Pindani M, Maluwa A, Nkondo M, Nyasulu BM, Chilemba W (2013) Perception of People Living with HIV and AIDS Regarding Home Based Care in Malawi. J AIDS Clin Res 4: 201. doi:10.4172/2155-6113.1000201

Page 5 of 5

those that had received adequate information and support from their care givers while at home as also reported by Ndaba [19].

Lack of resources, stigma and discrimination were major obstacles for most PLWHA in Malawi. These PLWHA were widowed and did not have a steady source of income from gainful employment or business due to the chronic nature of the disease. The stigma and discrimination against PLWHA may be due to myths in the communities such as the belief that HIV can be transmitted through sharing of dishes or cups with the patient which is an indication of lack of knowledge [17]. Stigma and discrimination directed at PLWHA has a lot of implications on the fight against HIV and AIDS. It does not only make it difficult for people to come to terms and manage their illness on a personal level, but it also interferes with attempts to fight the AIDS epidemic as a whole [21].

The results show that families that care for the PLWHA need assistance with physical care and a place where to discuss their fear as also reported by Chikalipo [12]. Despite these hardships, most care givers who are close relatives expressed the desire not to give up but continue looking after their patients as also reported by White [22].

\section{Conclusion}

The PLWHA perceive home based care to be beneficial to them despite challenges such as lack of transport to the health facilities and limited resources and knowledge on the part of their caregivers. The noble task of home based care of PLWHA has been left entirely to the close family members who are overburdened with responsibility. In turn, this has adversely affected the accomplishment of other equally important household chores by the family members. Health workers and volunteers only complimented the noble tasks that are performed by the close family members. Stigma and discrimination is another challenge for the PLWHA which is practiced by distant relatives and other community members and is mainly practiced due to lack of knowledge especially on how HIV is transmitted.

\section{Recommendations}

Authors recommend that care givers who are close family members should be provided with emotional, material and financial support to render quality care to their relatives who are living with HIV and AIDS. There is need for the government to equip caregivers with skills through training to provide quality care. Further, there is need for community sensitization and mobilization regarding the care for PLWHA. All stakeholders such as communities, NGOs, community volunteers should render their support to the family members so that they do not shoulder all the burdens alone in the care of their chronically ill PLWHA.

\section{Study limitation}

The study participants were drawn from urban and peri-urban areas of Lilongwe district and therefore the results may not be generalized to portray the perception of PLWHA towards the home based care in Malawi.

\section{Acknowledgement}

This study was funded by the University of Malawi through Kamuzu College of Nursing as part of PhD studies for the senior author.

\section{References}

1. National Statistical Office (2010) Malawi Demographic and Health Survey. National Statistical Office (NSO), Zomba, Malawi.

2. WHO/UNAIDS (2000) Draft working document: Key elements in HIVIAIDS Care and Support, Geneva.

3. Global Challenges / HIVIAIDS Cases decline in Malawi (2008) Testing, Counseling Sites Increase, Health Officials says. Kaiser Daily HIVIAIDS Report, 2008.
4. Stanhope M, Lancaster J (2004) Community and Public Health Nursing. (6 $6^{\text {th }}$ Edn.), Mosby, St. Luis.

5. Kamphinda S (2004) Lives experiences of children from families with HIV and AIDS Home Based Care patients in Lilongwe City North. M.Sc. Thesis, University of Malawi, Kamuzu College of Nursing, Lilongwe, Malawi.

6. Communities provide HIV and Tuberculosis care in Malawi (2008) Communicating Development Research.

7. Miller IW, Bishop DS, Herman DS, Stein MD (2007) Relationship quality among HIV patients and their caregivers. AIDS Care 19: 203-211.

8. Browning E (2008) Bringing HIVIAIDS Care Home: Investigating the value and impact of Community Based Care in Botswana, Associated Colleges of Midwest Society and Culture in Africa. Gaberone, Botswana.

9. Byrne MM (2001) Evaluating the findings of qualitative research. AORN J 73 703-706.

10. Malawi Ministry of Health (2003) Guidelines for use of Antiretroviral Therapy in Malawi. Ministry of Health, Malawi.

11. Campbell S (2004) Care of HIVIAIDS patients in developing countries. Primary Health Care 14: 22-25.

12. Chikalipo M (2007) Analysis of Community Home Based Care in Malawi. M.Sc. thesis, Queen Margaret University, Edinburgh, UK.

13. Mahommad N, Gikonyo J (2005) Community Home Based Care (CHBC) for PLWHA in multi-country HIVIAIDS programs (MAP) for Sub Saharan Africa African Regional Working Paper Series No 88.

14. Youseef F, Wong R (2002) Educating clinicians to assess quality of life in patients with chronic illness. Home Health Care Management and Practice 15: 20-26.

15. Caring for AIDS patients at home in Malawi (2008) Communicating development research.

16. Tsasis P, Tsoukas C, Deutsch G (2000) Evaluation of patient satisfaction in a specialized HIVIAIDS care unit of a major hospital. AIDS Patient Care STDS 14: $347-349$

17. Berhane Y, Zakus D (1995) Home care for persons with AIDS: community attitude in a neighbourhood of Addis Ababa, Ethiopia. East Afr Med J 72: 626630.

18. Nkhandwe FF (2001) Knowledge and attitudes of the family members towards HIVIAIDS home based care in 22 villages of Ekwendeni hospital catchment area, Malawi. M.Sc. thesis, University of Malawi, Kamuzu College of Nursing Lilongwe, Malawi.

19. Ndaba-Mbata RD, Seloilwe ES (2000) Home-based care of the terminally ill in Botswana: knowledge and perceptions. Int Nurs Rev 47: 218-223.

20. Mwinituo PP, Mill JE (2006) Stigma associated with Ghanaian caregivers of AIDS patients. West J Nurs Res 28: 369-382.

21. (2008) Stigma, discrimination and attitudes to HIV and AIDS

22. White KD Abrew N, Auret K, Graham N, Duggan G (2008) Learn Now; Live well: an educational programme for caregivers. Int J Palliat Nurs 14: 497-501. 